\title{
Blood Pressure Finding
}

National Cancer Institute

\section{Source}

National Cancer Institute. Blood Pressure Finding. NCI Thesaurus. Code C54707.

A test result that reports the diastolic and systolic pressure of the blood. 